\title{
Comparing the Proficiency Level of Bilingual Adult Users of English: The Ways of FL Excellence of Out-of-School Age-Focused Lifelong Education
}

\author{
Mateusz Pysz ${ }^{\circledR}$, Krzysztof Polok $®$ \\ Department of Humanities, University of Bielsko-Biała, Bielsko-Biała, Poland \\ Email: sworntran@interia.pl
}

How to cite this paper: Pysz, M. and Polok, K. (2020) Comparing the Proficiency Level of Bilingual Adult Users of English: The Ways of FL Excellence of Out-of-School Age-Focused Lifelong Education. Open Access Library Journal, 7: e6412. https://doi.org/10.4236/oalib.1106412

Received: May 11, 2020

Accepted: July 5, 2020

Published: July 8, 2020

Copyright $\odot 2020$ by author(s) and Open Access Library Inc.

This work is licensed under the Creative Commons Attribution International License (CC BY 4.0).

http://creativecommons.org/licenses/by/4.0/ (c) (i) Open Access

\begin{abstract}
Sustaining English proficiency level is important in present word circumstances. In this article, we will look closer to the possible influence on sustaining language proficiency taking into consideration various aspects. With the help of questionnaires and proficiency test, we will try to determine if some activities can have potential influence in terms of sustaining English language proficiency. In the end, we will focus on the result from the research and try to answer the earlier mentioned question.
\end{abstract}

\section{Subject Areas}

Education

\section{Keywords}

Computer Games, Lifelong Education, Bilingualism, FL Excellence, Adult Learners

\section{Introduction}

The world is changing very quickly, our approach to foreign languages is changing also. Today, knowing a second language is considered as something normal or even required to be able to function properly in the present world. Nobody is asking his or her self the question: "what is the purpose and reason for me to know a second language in my life?". For most of us, it is obvious that it is required to represent some level of knowledge in terms of a foreign language. As the English language is the most popular language today, we will take it as our basis. Most of us are learning it in the school, with more or less satis- 
factory for our needs proficiency level. Everything is in order until we end our education in school. What if we are not using it in our work and we are not learning it form that day. Some people are doing various things sometimes consciously and unconsciously. In this case, this "thing" would be self-learning. In [1], we get a definition of this phenomenon: "self-directed learning" describes a process by which individuals take the initiative, with or without the assistance of others, in diagnosing their learning needs, formulating learning goals, identify human and material resources for learning, choosing and implement appropriate learning strategies, and evaluating learning outcomes. Obviously, the above description is purposefully wide; but what if we focus on the things we do anyway (such as making use of a computer a mobile phone or a tablet) during our life and make an attempt to check if those activities help sustain the FL proficiency level on a level higher than the one the people who normally do not get involved in such activities may have.

Here, we will have to include one more important factor-that is motivation. According to [2], we have to pay attention to two at least types of motivation: intrinsic motivation and extrinsic motivation. In the situation, we are interested in, we will focus on the first type; as we want both the media and the equipment that can help us make use of each of the media-operating instruments to pair our daily activities, we want them to inform us about everything contemporary life can hardly function. Such a situation naturally increases the frequency of use of the activities that let us be informed, instructed or relaxed, each time with evident help of the language of use. In the majority of these situations, the language of instruction is English, what should motivate the (non-native) users to get back to the language they studied some time ago and reached some level of proficiency after they had completed their secondary/college FL courses. In this article, we would like to check if certain (mostly relaxation inducing) activities can have any influence on sustaining English language proficiency, as well as what types of such activities can possibly be recognized as more useful than others.

\section{Research}

\subsection{Method}

The methods conducted for this research can be categorized into two groups. The first method is survey research. This method was chosen because it provides the opportunity to collect a lot of pieces of information from various types of people. For this research, it was necessary to collect at least 100 respondents who do not use English in their work and do not learn English in a way of classes etc. The second method was combined with the surveys, it was a reading proficiency test. The aim of this test was to observe the level of English proficiency of respondents and compare it with the answers from the surveys to find some correlations.

\subsection{Participants}

The participants we need to complete the research come from various environ- 
ments. In order to increase the possible number of respondents, a method called snowball sampling was used. The participants were filling their answers through the internet which gave the opportunity to get various possible results.

In order to sketch the portrait of the survey participant we asked them about the following: 1) the age division of the survey participants looked as follows: a) 20 - 30 years old $(75.2 \%)$, b) 31 - 40 years old $(20.3 \%)$, c) over 41 years old (4.6\%). 2) level of education completed by them splitting among; primary education $(4.6 \%)$, secondary education $(4.6 \%)$, vocational school $(60.1 \%)$, higher education $(30.7 \%) ; 3)$ the type of work they did for the living: physical $(48.4 \%)$ or mental $(51.6 \%)$; 4 ) heir place of residence: city $(64.1 \%)$ or countryside $(35.9 \%)$; 5) the period of time that passed from the moment they concluded their mandatory language education: less than five years (54.9\%), six to fifteen years (37.9\%), more than sixteen years: $(7.2 \%) ; 6)$ the level of FL proficiency they would be able to declare: poor (34.9\%) or communicative (65.1\%); and, finally, 7) whether their parents spoke English at a poor (28.8\%) or communicational (71.2\%) level.

\subsection{Instruments}

Our research was based upon two principal instruments: a questionnaire and a reading proficiency test. The questionnaires consisted of 22 easy to fill questions. There were three types of questions: 1) individual-choice questions; 2) Likert-scale questions; and 3) questions based on tables with answers to choose from.

The proficiency test referred to an intermediately difficult text which was to be read by each of the research participants; subsequently, each of them was expected to complete a test modeled on the IELTS test; after completing it, in order to indicate the accurate level of proficiency of each of the testees, their results were transferred into the CEFR points with the help of an adequately prepared table.

\subsection{Procedures}

The survey and proficiency test were created with the help of computer and sent through the internet onto various forums and groups possible to be found. The posts were created in the way, that possible respondents would know the research principally refers to the people who do not use their English when at work, nor learn it in any type of classes etc. We were interested in the people who, after having completed their FL (English) courses, were still expected to make use of their already obtained language knowledge while making use of their internet, playing games and/or watching films.

\section{Results}

The first survey question we were interested in was their individual assessment of the current level of English. In this question, the respondents were asked to 
mark their answer on the scale, consisting of seven levels where level one stands for very bad and level seven stands for very good. The question was: "How do you assess your level of English right after leaving school?". The answers we received results are as follows: very bad (5.2\%), poor (6.5\%), average (18.3\%), neither good nor bad (22.9\%), rather good (22.2\%), quite good (13.7\%), and, finally, good (11.1\%). As one can see, the respondents are of quite a positive opinion about their level of knowledge of the foreign language they learned while attending their mandatory language education. More than a half of the respondents declare that they recognize their current level of FL proficiency as not to poor, average, quite good or even good enough to make use of it when getting in touch with the foreign language they have to make use of while reading FL orders, remarks or indications.

Naturally, we were interested in what had made them offer such declarations. This is why we asked them to assess the level of their mandatory English classes they participated in when attending their schools. As usually the Likert scale they were requested to complete went from very poor (1) up to very positive (7) and looked as follows: $1-8.5 \%, 2-10.5 \%, 3-23.5 \%, 4-21.6 \%, 5-19.6 \%, 6-9.2 \%$, $7-7.2 \%$. As one can see, their assessment was positive enough as $45.1 \%$ of the respondents were of the opinion that they had learnt something useful while taking part in the FL classes offered to them in their secondary (or higher) levels of education. Such an opinion may suggest that the respondents of our survey not only accept the forms of education they participated in when they had attended their schools, colleges or universities, but also assess them as personally useful.

Such an opinion is definitely strengthened by the result achieved in one more question of the survey in which we asked the respondents to assesse the level of easiness of their use of English. The Likert scale based results we received look as follows: $1-2.6 \%, 2-8.5 \%, 3-11.1 \%, 4-23.5 \%, 5-22.2 \%, 6-18.3 \%, 7-13.7 \%$. Such an answer may suggest that more than $3 / 4$ of the participants of the poll were of the opinion that they did not waste the time they had spent in their schools or colleges and feel quite satisfied because of that. What is more, they may also stress the fact that school/college/university FL education are these forms of language education that truly help the learners in their future language-based forms of FL communication.

One more poll question that strengthens this opinion is the one that concerns the respondents' assessment of the way they are able to apply the rules of English grammar (and/or writing), while producing their FL messages. When answering this question their opinions also ranged quite high, as their Liker-sale based answers looked as follows: $1-7.2 \%, 2-8.5 \%, 3-17 \%, 4-19 \%, 5-24.8 \%$, $6-13.7 \%, 7-9.8 \%$. One more time the respondents' opinion concerning the usefulness of their former classroom FL activity appears to be more than positive, strongly indicating their firm belief that what they had done when in school was not wasted by them at all. What's more, their belief that their classroom education had not been useless is clearly underlined by their next Likert scale 
based question that concerns the level of their present FL (English) proficiency. Following the requirements specified there, we achieved the following results: $1-2.6 \%, 2-7.2 \%, 3-13.7 \%, 4-24.8 \%, 5-26.1 \%, 6-17 \%, 7-8.5 \%$. As one can see, one more time the achieved results indicate that the effort of their FL (English) teachers was not assessed as useless as more that 3/4 of the poll respondents recognized their current possibilities as positive (or even more than positive).

In the next poll question we asked the respondents where they mostly use their FL skills, giving them the following options: 1) at home; 2) when on holidays; 3) when in contacts with friends; 4) while playing computer games; 5) while listening to music; 6) while watching movies; 7) while watching TV series; or 8 ) while reading books/articles/newspapers. The received answers show that the participants mostly make use of the achieved proficiency when playing computer games $(82.4 \%)$, to be followed by the following results: 1) $20.3 \%, 2$ ) $62.1 \%$, 3) $38.6 \%$, 4) $54.2 \%$, 5) $73.9 \%$, 6) $47.1 \%$. This answer also indicates the ways the poll participants make use of the FL (English) language they had acquired when taking part in their mandatory FL classroom activities. Having been given an array of possibilities, the following (Likert-scale) answers were achieved; 1) listening to English music (54.2\%); 2) speaking FL (English) at home (20.3\%); 3) playing computer games where English is present (82.4\%); 4) reading English books, articles, newspapers etc. (47.1\%); 5) watching movies/TV series in English (73.9\%); meetings with the friends (38.6\%); communication during vacations $(62.1 \%)$. As one can see, playing computer games has appeared to be the most popular outdoor activity declared to be performed by the poll participants. Such answers clearly indicate that the acquired FL proficiency has been recognized as the poll participants as mostly receptive (rather than productive) from FL activity. An answer like this suggests that the whole process of FL education has been arranged to help F:L learners receive rather than produce a message; it is in this way the FL users are generally expected to receive the information rather than produce them. Needless to say that this way of message involvement stands against the whole process of message handling whether the process of message production equals the one of message reception. What is more, it is believed the processes of message production and reception ought to be reported as more or less functionally equal as any form of technical discrepancy indicates some form of FL inability of the language users. Any such inappropriate productions may therefore indicate a form of inappropriate (and incorrect) organization of the message to be expected by the message authors.

We were also expected to find the FL learners that may not be equally motivated to learn a FL what may result in the construction of their attitude to learn the language by each of them. This is why we asked a question connecting their everyday usual activity recognizing the scope of the language re-learned by them. Our question referring to the use of the foreign (English) language by each of the poll participants reached the following answers: $1-5.9 \%, 2-9.2 \%$, $3-19.6 \%, 4-9.8 \%, 5-15.7 \%, 6-14.4 \%, 7-25.5 \%$. As can be observed there two at least of groups of FL language users-the ones that do not necessarily find 
its everyday necessity (19.4\%), and the ones that are in need of its everyday application (39.9\%). It is the second group that slightly prevails here, what may mean that-despite everything — the use of a foreign language is recognized as (a little bit) more important that the use of knowing it only.

Following the previous question, we were also interested in learning in what everyday activities the poll participants recognized a necessity to introduce their FL abilities. The received answers indicate the following spheres of FL use suggested by us (Table 1): listening to English music; playing computer games where English is present; reading English books, articles etc.; watching movies/TV series in English; meetings with the family; communication during holidays. As one can easily observe it is the individual forms of English which are mostly appreciated by the poll participants. In the majority of the specified spheres of FL applications, it is the seventh (highly personal) area which was mostly appreciated (and indicated) by $\mathrm{f}$ the participants. With the exclusion of the issue Meetings with the family, where the largest amount of the participants clearly indicated that they were not willing to make use of the language in such situations, in most of the remaining issues it is the last pigeon-hole which was voluntarily selected by the participants. Such a selection may indicate that most of the former FL classroom learners recognized their former FL activities as definitely useful and are currently able to make use of them in the way they think to be most needed and most suitable to help them recognize themselves as active members of the message production market.

A series of the Likert-scale questions that followed, focused on our attempt to discover these FL activities which are mostly preferred by the survey participants. This is why we were interested whether-after they had completed their secondary/higher FL education, they were still able to make use (or sustain) their FL proficiency when 1) reading books, articles etc. in English; 2) watching original TV series etc. in English; 3) listening to English songs passively (41.8\%), or actively $(51.2 \%)$; 4) playing computer games, in which English is used; and finally, 5) are able to communicate in English with other (native and non-native) users of the language. The results we obtained are presented in Table 2.

As not all computer games require active linguistic involvement of the players in the game, we also asked the poll participants what computer games they usually get involved in. The games that were included in our research were either online or offline games and included the following ones: MMORPG, RPG, FPS, RTS, sport games, racing games, MOBA. Having confronted them with the research participants we found the following results (Table 3 ).

It was found out that the games which were mostly liked by the poll participants were the FPS online as well as RPG ones, both of them requiring a considerable level of FL proficiency. Both the indicated application and the general popularity of such games offer an informative tendency that it is the reception games (i.e. the ones practicing various reception orders and/or other forms of passive behavior) that have appeared to become the most popular ones. It is in 
Table 1. Spheres of using school-internalized forms of English (own elaboration).

\begin{tabular}{|c|c|c|c|c|c|c|c|}
\hline Activity & 1 & 2 & 3 & 4 & 5 & 6 & 7 \\
\hline Listening to English music & $13.0 \%$ & $28.1 \%$ & $20.9 \%$ & $13 . .0 \%$ & $9.8 \%$ & $3.9 \%$ & $11.1 . \%$ \\
\hline $\begin{array}{l}\text { Playing computer games where English is } \\
\text { present }\end{array}$ & $3.3 \%$ & $9.8 \%$ & $22.2 \%$ & $13 \%$ & $8.5 \%$ & $16.3 \%$ & $26.8 \%$ \\
\hline $\begin{array}{l}\text { Reading English books, articles, } \\
\text { newspapers etc. }\end{array}$ & $9.2 \%$ & $10.5 \%$ & $20.3 \%$ & $11.1 \%$ & $9.8 \%$ & $18.3 \%$ & $20.9 \%$ \\
\hline Watching movies/TV series in English & $2.6 \%$ & $10.5 \%$ & $22.2 \%$ & $13.0 \%$ & $14.4 \%$ & $13.7 \%$ & $23.5 \%$ \\
\hline Meetings with the family & $12.4 \%$ & $62.7 \%$ & $10.5 \%$ & $5.9 \%$ & $2.6 \%$ & $2.0 \%$ & $3.9 \%$ \\
\hline Communication during holidays & $7.2 \%$ & $7.8 \%$ & $21.6 \%$ & $9.2 \%$ & $11.1 \%$ & $15 \%$ & $28.1 \%$ \\
\hline
\end{tabular}

Table 2. The forms of use of the FL already learnt by the research participants (own elaboration).

\begin{tabular}{|c|c|c|c|c|c|c|c|}
\hline Activity & 1 & 2 & 3 & 4 & 5 & 6 & 7 \\
\hline Reading books etc. in English & $41.0 \%$ & $13.1 \%$ & $13.1 \%$ & $6.6 \%$ & $6.6 \%$ & $1.6 \%$ & $4.9 \%$ \\
\hline Watching original TV series etc. in English & $5.0 \%$ & $5.0 \%$ & $11.4 \%$ & $20.7 \%$ & $23.7 \%$ & $19.7 \%$ & $15.0 \%$ \\
\hline $\begin{array}{l}\text { Listening to English songs (passively or } \\
\text { actively) }\end{array}$ & $0.0 \%$ & $2.7 \%$ & $4.8 \%$ & $6.8 \%$ & $10.9 \%$ & $19.0 \%$ & $55.8 \%$ \\
\hline $\begin{array}{l}\text { Playing computer games, in which English is } \\
\text { used }\end{array}$ & $3.5 \%$ & $2.8 \%$ & $8.5 \%$ & $14.1 \%$ & $14.1 \%$ & $21.1 \%$ & $35.9 \%$ \\
\hline $\begin{array}{l}\text { Communicating in English with other (native } \\
\text { and non-native) users of the language }\end{array}$ & $5.9 \%=$ & $5.9 \%$ & $13.7 \%$ & $12.4 \%$ & $23.5 \%$ & $15.7 \%$ & $22.9 \%$ \\
\hline
\end{tabular}

Table 3. Types of computer games used by the poll participants (own elaboration).

\begin{tabular}{cccc}
\hline Name & $\%$ & Name & $\%$ \\
\hline MMORPG & $52.9 \%$ & Sport games-online & $31.4 \%$ \\
RPG & $61.4 \%$ & Sport games-offline & $43.8 \%$ \\
FPS-online & $63.4 \%$ & Racing games-online & $24.8 \%$ \\
FPS-offline & $49.7 \%$ & Racing games-offline & $43.8 \%$ \\
RTS-online & $18.6 \%$ & Other-online & $21.6 \%$ \\
RTS-offline & $37.3 \%$ & Other-offline & $26.1 \%$ \\
MOBA-online & $26.1 \%$ & Do not play-online & $2.6 \%$ \\
MOBA-offline & $18.3 \%$ & Do not play-offline & $2.0 \%$ \\
\hline
\end{tabular}

these games where the language proficiency is mostly (i.e. with some rare exclusions) limited to the processes of message understanding and subsequent skillful performance of the required forms of activity. The situations that truly require some other forms of active behavior are rare and limited to a number of specially evoked situations. Normally, the players are requested to follow the suggested orders, as it is mostly this form of behavior that should help one become a game winner.

In the two last questions of the poll we asked the participants about their im- 
pressions concerning their former mandatory FL education and whether, while attending their school, they took part in any other everyday form of everyday schooling (such as private tutorials for example). While answering the first question we were able to obtain the following (Likert scale based) results: $1-20.3 \%$, $2-10.5 \%, 3-17.6 \%, 4-18.3 \%, 5-11.1 \%, 6-9.8 \%, 7-12.4 \%$. At the same time, the question concerning private tutorials was answered in the following way: $1-28 \%, 2-11 \%, 3-17.1 \%, 4-13.4 \%, 5-19.5 \%, 6-4.9 \%, 7-6.1 \%$. It is easy to discover that although the poll participants were not fully satisfied with their school/college education they still were willing to accept it as this was the only form of FL education they had been offered. The majority of them either did not afford taking part in the out-of-school language lessons or did not want to take part in them. Thus, basing upon mandatory school education, mostly focused upon passive rather than active forms of FL performance, it appears to become this, sufficient enough, form of FL activity that is needed to actively perform in most of the leisure games found in the net.

\section{Proficiency Test}

When asking about their past senior/junior high school and/or university FL experience we requested them to disclose the grade they received as the final one, that concerned their education there. We needed this information as we wanted to find out whether our earlier assumption concerning positive results of one's involvement in such relaxing forms of FL activity holds sense. Having obtained such results we were able to ask the poll participants to take part in their online chat-like test of FL proficiency that was based upon the knowledge they were expected to have possessed when completing their mandatory language education. The test designed by us was based upon the standard battery of tests offered by CEFR that can be found on the internet. The proficiency test results turned to be as follows: A1-7.8\%, A2-14.4\%, B1-26.8, B2-26.1\%, C1-18.3\%, $\mathrm{C} 2-6.5 \%$ (the letters before the percentage results indicate the levels of proficiency fund $n$ CEFR).

\section{Discussion}

From the research, we get information that most of the respondents $(75.2 \%)$ are 20 to 30 years old. As for their education, we have found that the majority (60.1\%) have completed their senior high schools; there was also quite a big group $(30.7 \%)$ of respondents that have declared having completed their college studies. More than a half of them live in the cities (64.1\%). It can be of interest that $71.2 \%$ of the respondents declared that their parents did not use a foreign language communicatively. As more than a half of the respondents completed their education in the period less than 5 years ago, we can assume that the influence from the school can still be plausible. When it comes to the (Likert scale-based) self-assessment of their level of English after school by respondents, one can find out that most of the respondents declared their mandatory educa- 
tion to have been completed with the grades fair (C), or passable (D). Most of them claim that their level of English was neither bad nor good. Generally, the respondents were not satisfied with their language education when in their schools. Such an impression can be drawn from the respondents' opinions concerning their assessment of the years they spent in their schools. When asked to assess their speaking abilities, most of the answers circulate around 4 (neither bad nor good) out of 7 on the Likert scale, with a growing tendency to utter mild satisfaction of using the language, as there are more people who reveal they can talk (rather than cannot) in English. In respect to the respondents' declarations concerning the application of correct grammatical issues, most of the respondents ticked 5 (rather good) out of 7 on the Likert scale. This result is interesting because we can see that the issues that concern the application of theory-based syntax are rated higher than practice-requiring skill of speaking. It gives the impression that for more people it would still be easier to write something rather than to make a conversation.

We need to remember that our respondents are people who do not need their English skills at work and they do not learn it taking part in additional lessons. This is why the question concerning the situations they mostly use their English, they were able to mark different answers. Naturally, the largest group of people (82.4\%) chose the option "during the computer games sessions", but $73.9 \%$ of them indicated that they mostly use it when they watch various shows and programs, $62.1 \%$ ticked "on vacations", $54.2 \%$ underlined "while listening to music" and $38.6 \%$ declared that they need it to talk to their foreign friends. When we asked about the frequency of using English the majority (25.5\%) ticked the highest option (7) on the Likert scale.

We also asked them to choose one common enough activity which, in their opinion, makes using English indispensable. A little bit to our surprise it turned out to be a possibility to communicate during holidays (33.5\%), which surpassed playing computer games where English is present (19.3\%). The remaining moderately highly assessed activities were: 1) watching TV shows and programs in English (17.2\%); 2) reading English books, articles etc. (13.0\%); 3) listening to English music (12.3\%); and, finally, 4) meeting with friends/family (4.7\%). It should be noted that despite of the biggest influence of communication during vacation the frequency of possible presence of this activity is not as high as the other activities.

As specified above, when calculated globally (i.e. counting all the ticks performed by the poll respondents), one of the most popular everyday activities that have been recognized by them turned to be playing computer games (this possibility was ticked by $90.2 \%$ of the respondents). When asked about the frequency of participation, the largest group marked 7 out of 7 on the Likert scale. To be more specific, the most popular genres are the ones of MMORPG, RPG and FPS types. The first two mostly contain a lot of background and a story to be processed individually by the players. The MMORPG games have the on-line 
aspect, what means that, besides going through game story, the players need to communicate with other players through writing messages which give them an opportunity to use English in order to achieve some specific goals. A similar situation is with respect to the FPS type of games. In this situation, the players are mostly required to communicate on-line with other players. Playing an FPS game forces them to speak in English, using it in many adrenaline-filled stressful situations where there is no time for delay. They need to be fast and accurate. This type of situation forces players to use English without a moment of hesitation they might have needed, thus becoming a naturally applied activity for them.

We asked the players to illustrate the level of their language proficiency while playing a game like that; on the Likert scale they were requested to tick one of the seven possibilities (1-very poor; 7-very good) Subsequently, in order to discover the level of correlation between the level of presented language proficiency of all the poll participants and the level of proficiency of these participants who have declared themselves to be (more or less) proficient MMORPG, RPG and FPS players we decided to find out the Pearson correlation coefficient $r$, it turned out to be 0.76 , which is positive and strong (Figure 1 ).

It appears that most of the computer game players do quite well when being involved in such games. Most of them state that active involvement in a MMORPG, RPG and FPS game, where a more or less fluent use of English is expected, does not produce a serious problem to them. What is more, they mostly indicate that playing such games is recognized as a form of additional language (English) practice and as possibility to acquire a number of new and hardly used expressions. They are of the opinion that the game is definitely more difficult to go through when that does not know it; however, after they have played it for a couple of time and deciphered the expressions they are expected to make use of when playing the game appears to be much easier and much more comfortable to play.

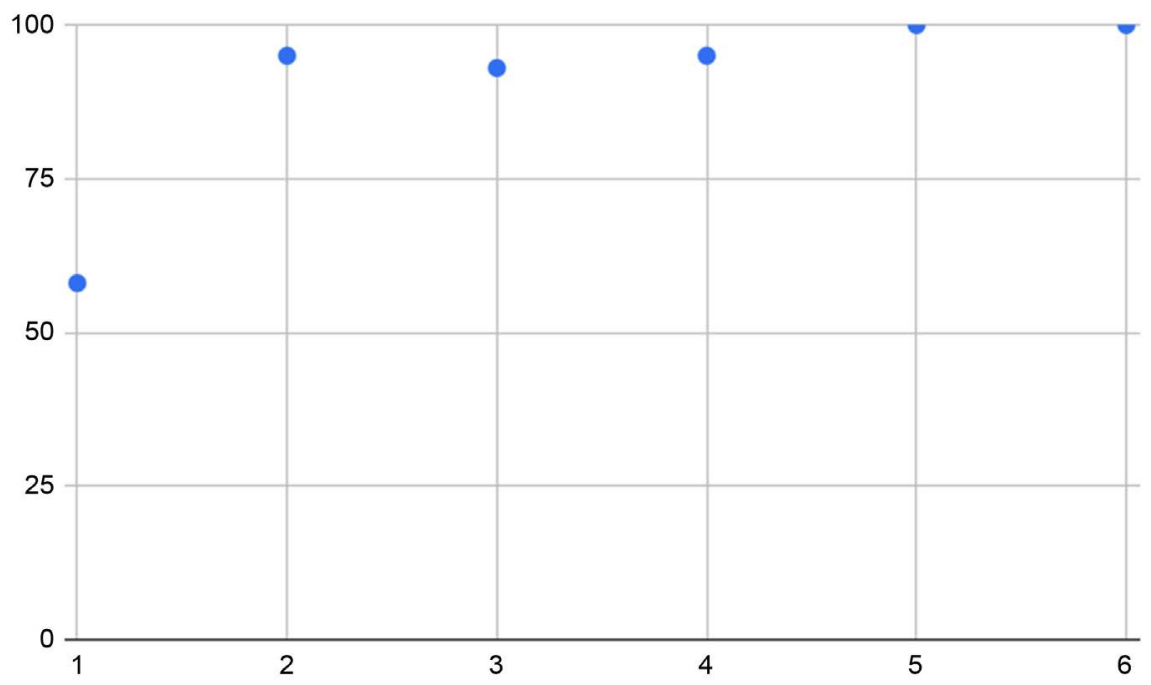

Figure 1. Pearson $r$ correlation coefficient for the levels of FL proficiency of computer game players. 


\section{Conclusion}

The principal question that we were pursuing in this research was whether the mandatory FL education future computer game players, as well as other postmandatory FL education users, can be of help in their everyday activities. We also wished to find out if the process of mandatory FL education most of the adults were subjected to can be aided by various (and often unexpected) stimuli they approach in their everyday adult activities. Finally, we were interested in their attempts they are willing to perform to overcome such unexpected predicaments and whether their past linguistic knowledge can be helpful here. While assessing the proficiency test results, we have found that the largest group of respondents are those concentrated around (good and quite good) B1 and B2 level, to be followed by, respectively, (poor and quite poor) A2 and A1, (fluent) $\mathrm{C} 1$ and, finally (native-like) $\mathrm{C} 2$. What is more, we have also spotted a form of evident tendency among the respondents; the level of English proficiency is growing alongside the number of positive answers considering questions about the activities where the English language is present they have ticked. A conclusion linking the higher positive number of answers with the higher proficiency level can be drawn. It can also be assumed that all, mentioned earlier, FL-related activities the adult respondents take part in exert positive influence on sustaining proficiency levels among them, additionally helping retrieve the knowledge the respondents received from their mandatory school education. Definitely, such efficiency levels appear to be individual and depend on the way a given person makes use of the past knowledge; at the same time, it has to be assumed that repeated involvement in an activity results in gaining more potential and educational feedback from it, be it playing computer games, reading books or newspapers in English, or watching English films, for example. All the forms of individual involvement in the FL practicing activities can turn to be effective; however, considering the feedback gained from the respondents, although all of them have their potential, some of them are more popular and effective than others.

\section{Conflicts of Interest}

The authors declare no conflicts of interest regarding the publication of this paper.

\section{References}

[1] Knowles, M. (1975) Self-Directed Learning. Association Press, New York.

[2] Kordziński, J. (2007) Motywacja-tajemnica szkolnych sukcesów. [Eng.: Motivation-A Secret of School Successes]. Warszawa, Verlag Dashofer Ltd., Berlin. 